\title{
Development of Communication among the Members of the Youth Policy
}

\author{
Yulia S. Obidina ${ }^{1}$, Svetlana V. Rybakova ${ }^{1}$, Tatyana V. Smyshlyaeva ${ }^{1}$, Roman V. Belorusov ${ }^{1} \&$ Pavel S. Kozlov $^{1}$ \\ ${ }^{1}$ Mari State University, Yoshkar-Ola, Russia \\ Correspondence: Yulia S. Obidina, Faculty of History and Philology, Department of General History of the Mari \\ state university, Lenin Square 1, Yoshkar-Ola, 424000, Russia.
}

$\begin{array}{lcc}\text { Received: February 21, } 2015 & \text { Accepted: March 15, } 2015 & \text { Online Published: April 29, } 2015 \\ \text { doi:10.5539/res.v7n8p335 } & \text { URL: http://dx.doi.org/10.5539/res.v7n8p335 }\end{array}$

\begin{abstract}
The article describes the main activities of Mari State University (city Yoshkar-Ola) to create the homogeneous cultural space under the youth policy. One of such activity was the creation of the united information and communication portal "Muraveynik" ("Anthill") on the basis of the university, which purpose is the consolidation of Russian students in the united information social and cultural space. Based on the successful experience of the realization of information and communication projects in Mari State University, it is instructive to spread this model of interaction on the national basis. The given resource has to unite all the information related to the realization of the youth policy in the country and allows the youth and the students to orient effectively by choosing educational, professional, leisure strategies of the youth. The article also deals with the experience of the youth policy, the social studies, the volunteering in Mari State University which allowed to apply successfully the latest technologies for the purposes of the social integration of the region and the country as a whole. The group of the authors is the direct creator and coordinator of the presented model of the social and cultural, communicative interaction in the youth and the students space and hopes to find the associates to create safe, tolerant, high-technology information space to secure the cooperation among different universities and countries.
\end{abstract}

Keywords: communication, informatization, student movement, volunteering, youth policy, information portal, campus project, regional university

\section{Introduction}

The early XXI is characterized such phenomena in the society as globalization and informatization. Mediatization has affected all the fields of human activity, giving the opportunity of the versatile communication (Tavokin, 2011). On the one hand, it helps to develop the homogeneous cultural space but also raises the well founded fears of depersonalization and grading of cultural differences. These fears cause the other extreme in the society - the emergence of the social barriers, distancing from different culture bearers. Under the current conditions the leading role in smoothing of this conflict belongs to the education (Marjolein \& Herman, 2010). In the present model of the youth social and cultural practice in the Russian Federation the kernel of the modern youth is the student community. Thus, it seems reasonable to create a united communication and information system exactly on the basis of universities. Intercultural communication becomes an essential requirement, principle and paradigm of interaction of all members of the educational environment (Obidina, 2010).

In the Russian reality the central and regional universities are on the different poles of the social space-time "center-periphery" that results in contradiction between the cultural levels and peculiarity of cultural identity of the members of educational process which has different subject matter and configuration in each particular case (Khovanova, 2010). Mari State University belongs to the regional universities. The main task of these universities is to preserve and develop the intellectual potential of the region. This will be possible only if there is an effective communication system both intramural and in the educational space scale of the region and the country as a whole.

Mari State University completes an important task to preserve social, cultural potential and heritage of the Mari El Republic. Under modern political, economical, social and cultural phenomena the existence of Yoshkar-Ola and the republic as a center of education, science and culture depends mainly upon the activity of the university. 
The Mari El Republic is a multicultural and multi-confessional region. However, due to the integration of Russia into the world educational environment the doors of the Russian universities have opened for the youth of different countries and nationalities.

Mari State University is a multiple-discipline classical university with multilevel system of training. More than 80 years the university has met the educational requirement of the society and the country, developed fundamental and applied science, trained specialists for the region and the country. The modern stage of the development of Mari State University is characterized by a large regional campus with a wide range of implemented educational programs and an important scientific capability.

The university has an integrated role in training specialists for economical, social and cultural areas of life in the Mari El Republic. Mari State University is an exclusive center of academic training in physic, mathematics, chemistry, biology, agriculture, pedagogical education, humanities (history, philology, and journalism), physical training and sports, culture and arts.

One of the tasks of the university is to develop "cloud" infrastructure of the science and educational sphere and to improve the information safety; to form a high-tech science and educational center on the basis of Mari State University; to implement the system of management accounting, customer relationship management, means of business analytics (Development program of Mari State University for the period of 2014-2019 http://marsu.ru/Documents/UMU/2014/2014-2019.pdf).

Under the solution of application tasks there is an active work to establish the project "Muraveynik" on the basis of Mari State University which purpose is to develop an information environment of student associations of the universities in the Russian Federation.

Therefore, the purpose of the article is to acquaint wide scientific and creative community with the experience of Mari State University in the sphere of interaction of members of educational activity and the youth policy as a whole that is an example of a successful implementation of the latest information technologies in the perspective of social integration (Obidina, 2008).

\section{Materials and Methods}

The effective preparatory work was done for preparation and realization of the project. In Mari State University the united communication system was created and implemented on students' initiative which includes two main projects: Campus project (together with Sberbank of Russia OJSC) and united communication channel (together with Megafon OJSC).

\subsection{Campus Project}

In the modern information society when you can use the solutions of a large number of providers with the use of different Internet and gadget services to cope with a $\mathrm{n}$ assigned task the organization and a person who is a worker of such organization faces a problem - a huge number of passwords and identifiers to gain an access to a cherished service (Kwok, 2015).

Analyzed the experience of other countries and universities (Villanueva-Felez \& Molas-Gallart, 2013) the specialists of the university has considered several versions of possible decisions and offered the following scheme of rendering of services:

\section{1) Virtual identifier}

Virtual identifier is a user account which is given him/her at the moment of access grant to one of the systems of the university. When required to grant an access to another system he/she gets an appropriate access level to an early made account.

2) Physical identifier

Physical identifier is a campus card - chip bank card with the technology of contactless payments. For simplicity of authorization in the systems the chip is attached to the virtual identifier.

The system of identifiers makes it possible to keep the user information in one place: access to the services (rooms) of the university, financial information, information of library system, academic information, digital signature of a cardholder etc.

By using the qualified digital signature the educational institution has the right to switch to e-document management with students and carry out collection, check, determination, estimation and keeping works of the students (course papers, tests, graduate works etc.) in electronic form, each of the members of the process should sign the document with his/her digital signature after the performance of his/her transaction. 
Similar system of identifiers can be integrated into the developed portal "Muraveynik".

\subsection{United Communication Channel}

Among the operators of the great third (Beeline, MTS and Megafon) the one was chosen on a competitive basis for Mari State University-MegaFon OJSC offering more profitable terms according to the set of the requirements of the university.

The students and the staff enabled to the corporate tariff have received preferences of the use of communication services within the tariff. The works on projection and filling the architecture of data bases of all numbers and their holders were parallel done, communications protocol of number data bases with active systems of the university were adjusted for efficient collection and spread of the information. The interrogator was tested on the basis of the united communication channel.

The united communication system proved its efficiency in solving operative tasks both information and sociological character. But events proved the need to increase the sphere of realization of interrogations from cellular networks to Internet resources which can be the mobile application "Muraveynik" providing the access to the portal and its functions through the personal gadget.

Scaling of this communication model to the country will allow to collect and process the sociological statistic regardless of space, time and technical conditions.

The system also provides for the customer of the interrogation the flexible system setup for the tasks of the specific interrogation on the basis of filtration of respondents according to targeted criteria (sex, age, residence, social status) form the questionnaires from the user data base.

This form of sociological studies requires any costs neither from the organizers no respondents. The procedure of the interrogation for the responder is very simple: if he/she meets the requirements of the interrogation, he/she will receive automatically a message on the mobile phone with an offer to vote. The information is send immediately to the server where it is processed according to an early specified algorithm (Farrugia, Hurley, Payne, \& Quigley, 2011).

The offer of such forms of work has a deep foundation because there is a student center of sociological researches on the base of Mari State University, which purpose is to study the public opinion (first of all the youth) on different questions. For optimization of the interrogation of students in Mari State University the system of student sms-interrogation which is in the united data base, was created upon an initiative of Student and Graduate student Council together with MegaFon OJSC on the base of present project of Mari State University "United communication channel" in summer 2014.

On the formation stage the Center had several purposes such as research of social and economical problems of university training, study of professional orientation and their adaptation, also disclosure of a problem of physical training and formation of a healthy life style of students, participation of students in volunteering as a factor of their stable civic position, participation of students - volunteers in voting (Kozlov \& Obidina, 2014).

The students of Mari State University create and carry out questionnaires, social forms. Through the system of self-examination they discover their abilities, research different social, economic and legal aspects of their vital activity, raise the level of their knowledge and skills. The students under the activity of the Center were interviewers on the elections of the State assembly deputy in July-September 2014 through the interrogation of the citizens. The youth also take part in processing the received information through plotting, dependence, reveal of specified featured and properties thereby the students of Mari State University are the active researchers.

The center of sociological researches of students of Mari State University is an important tool in educational system of the modern university because it allows to carry out external and internal monitoring of the students, to correct forms and methods of work with the students.

Especially, the results received by the center of sociological researches showed that the students of the university feel extremely delicate the needs of the labor market and think fairly that the labor market needs high qualified specialists. One in two students of the university mentions that he/she requires in deep professional knowledge (55\%). The greatest need in deep professional knowledge was shown by the students of law faculty, faculty of electrical engineering (74\%), institute of economics, management and finances, institute of medicine and natural sciences $(72 \%)$, faculty of foreign languages $(64 \%)$ and institute of economics, management and finances $(62 \%)$. The need in communication skills was shown by $46 \%$ of students of the university. This confirmed the necessity to create the united information portal for creation and coordination of already existed skills by the students.

The sociological researches have also shown that the choice of profession is a very acute question for the youth. 
According to the range of importance of the motives to choose the profession the students gave the first place to creative interesting character of the work (56\%), the desire to get higher education is on the second place $(51 \%)$, the hope that the higher education increases the chance of finding a decent job is the third (50\%), the forth place is for altruism - the work is important for the country and for people (32\%). High salary is not an important motive for the students of most faculties/institutes by the choice of profession. The high salary is expected by the students of institute of economics, management and finances, faculty of electrical engineering (45\%), law faculty (42\%), faculty of physics and mathematics (12\%), faculty of physical education, sport and tourism (11\%). The developed project took into account these facts to create different tests and educational programs on estimation of the potential of each student who is the user of the portal.

However, the research has shown that $58 \%$ of the students are occupied with the social work at the university. $10 \%$ of responders can be related to the group of active students who deal with social work every day. But at the same time every second student would like to participate in student government, to render a social assistance to people in need (42\%). Shows, competitions, festivals are popular among the students of the university: $20 \%$ of students take part in them with pleasure or participate as viewers.

The desire of students to benefit the society (see Figure 1), to become active citizens of the country will also reflect in numerous applications, data bases created under the concerned project.

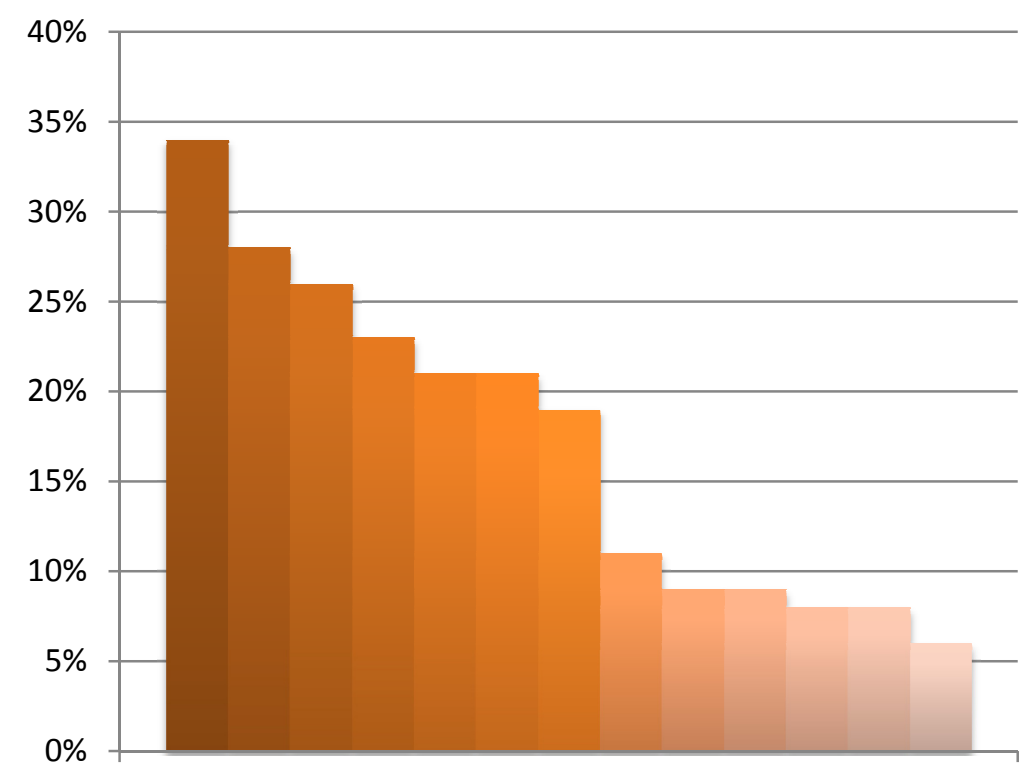

Figure 1. In what spheres of social helpful activities are you ready to help?

The desire of the students to participate in the life of the university, the region and the country as a whole made the university administration more active in creation of such project which would allow to connect desire and thoughts, the students, the teaching staff and the staff of the university together. Portal "Muraveynik" became this center of attraction.

Therefore, the purpose of the project in Mari State University specifies the need to overcome conflicting trends, the solution of the task for the modern education - to form the united space of intercultural communication which is a place for creative reconsideration of the total cultural experience, concurrence of public interests.

\section{Results and Discussions}

In the dynamic and constantly changing youth community new information appears regularly—every day, every hour, every minute. It is extremely important to deliver this information immediately, real-time to all interested members. The realization of this interaction model is possible only in creation of special communication network. Sufficient popularity of information and communication technologies among the citizens of the Russian Federation allows to make positive forecasts for active use of this network (Ershova \& Shaposhnik, 2013). 
Portal "Muraveynik" is an internal network of youth and student communities of the Russian Federation constituting different interactive services working under one site. The portal has data bases of events addressed to the youth and also services for join work with documents (Gao \& Bhiri, 2013). The "event" under this project is any event, product or service oriented to achieve educational purposes (information services, educational services, leisure services, employment services, etc.).

The portal is intended for performance of a range of functions for a successful functioning of the university in Russian and international space. One of its main functions is creation, reflection and organization of social interactions in student, youth space. In the opinion of the rector of Mari State University, M. N. Shvetsov, it is possible under the project to realize independent university ranking formed on the basis of various nonstandard criteria different from the used system of National university ranking.

For example, using this portal you can retrace the existence of a certain school of sciences or a world scientist, number of graduates-billionaires, anti-rankings etc. However, the portal provides a "delicate" filter setup, an opportunity to choose a university and/or an educational program according to unique needs of university entrants.

One of the planning functions of portal "Muraveynik" is an information support of the accreditation centers. In the modern world when information technologies play a great role in the development of everyday operations, the sphere of education suffers serious changes. To make the graduates required it is not enough to have only a strong brand, it is necessary to have modern courses and modern evaluation methods of results of each student.

To confirm the skills of a graduate it is essential to have a confirmation in hand which technologies he /she is able to use and according to what methods they were evaluated. To solve this task the Authorized test centers were opened in Mari State University which allow to pass a certified test and to get a certificate with a signature of a general director of a company-vendor in case of its successful passing.

Similar test centers are in many universities of the country so a need arises to provide an access to students to the free information about all these centers that they can compare and choose an interested educational program.

Portal "Muraveynik" is a web-portal - a system of Internet resources, interactive services which accumulate information addressed to the youth (contests, conferences, forums, etc.), creating by the Ministry of Education and Science of the Russian federation, student associations of universities and another interested institutions. The form of the project is not accidental-social networks are today one of the effective modes of communication in the youth sphere stimulating the exchange of ideas and self-organization of communicants (Elder, 2014).

According to the work the concerned project is something among a social network, reference and legal system and a corporate portal. The access to the portal is through the browsers, mobile and desktop applications.

Browser version of the product is a version used a browser interface to access the resources of the portal and not required to setup additional applications on the computer.

Mobile application is a program set up and started up on the mobile phone, communicator, smartphone etc. It is something like a desktop application but created especially for a mobile phone (smartphone).

Desktop application (from "desktop") is a program intended especially for the use of portal "Muraveynik" on a personal computer, isolated from other applications.

The functions of the portal:

1) Table of events including the function of reminder about terms.

2) Filter of events, system of drop-down lists and other options of setup of the user profile according to the sphere of his/her interests.

3) Electronic registration of a participant in the event.

4) Private cabinet of the user.

5) Formation of independent university rankings according to different criteria.

6) System of feedback (evaluation of an event by the participant).

7) System of interrogations and "student referendum".

8) Realization of student elections (student self-government, youth parliaments etc.).

9) Preparation and presenting of an analytics to interested members.

10) Electronic mail in the domain of the information portal. 
11) Video-translations and space bridges, on-line translation from great events:

- In the form of translations form cameras

- In form of hourly runarounds of "a recruit person" on the event (as a rule, students of "Journalism")

The central kernel of the portal is a data base of events held at universities of the Russian Federation and also events addressed to the youth. Each event is based with indication of terms and other important information which gives an understanding about an event to a visitor of the portal.

The held events will be the main "driving force" for the users and potential users. Each event has a taskbar with buttons: "go exactly to the event", "probably go to the event", "don`t go to the event"; "interesting" or "not interesting". Thus, there is an opportunity to follow the statistic of interest in an event.

There is also an opportunity to give a mark to an event. Each participant receives a message through mobile application "Muraveynik" on a personnel gadget to follow an impression about the event with an offer to give a mark at the beginning, in the middle and in the end of the event. Thus, it will be possible to follow the impression from the event in its process.

At the end of the event before its transfer to the archive within 14 days there is an access to the publication of comments for the event and its evaluation. It is also possible to create a technique of collection of opinions and marks of held event according to the questionnaire.

The organizers should give a detail report with different multimedia information about the event within 2 days after the event.

There is a double-phase realization of registration to take part in the event:

1) By the registration an open standard of decentralize authentication system will be used-Open ID (with the help of active account in a network and/or on a popular mail service).

2) After the registration to identify the profile and its activation it is necessary to complete a questionnaire and enter a sms-cod which will be send on the number of the mobile operator of the user specified by the registration. SMS-cod is an activator of a user account in "Muraveynik".

There are different categories of participation for user of the portal:

Administrator is a position which provides a full access to a system setup to carry out the following functions: installation and setup of the system; setup of the system modules; control of an access to the system, sites, users, groups of users; management of content of the portal; information protection, right to delete the user pages; right to limit the users in rights of editing and viewing the site, preparation and maintenance of backup copies, their terminal checkup and destruction etc.

Authors of the project, representatives of the Ministry of education and science of the Russian Federation can be administrators. Administrators are set at the Ministry of education and science level, their number is strictly limited. The conditions of entering and leaving the position of administrator are strictly regulated.

Moderator is a user having a partial access to a system setup, carrying out the following functions: adding a material into the system and its editing; deleting and editing another's messages; limitation of users in rights of editing and viewing the site etc.

Modarating is carried out by the advice of student associations of the universities and also by other organizations which are the organizers of the event addressed to the youth. Moderators are appointed by the Administrator. Moderator from the regional Ministry of education and science views all the student of the region. Moderatos carry out the full responsibility for information published on portal "Muraveynik". To coordinate the work it is suggested to create particular student committees of informatization at the level of entities on the base of regional associations of student associations.

One person is appointed to the role of moderator according to the following rule - it is necessary to fulfill the questionnaire to get the rights of moderator in each region from the following departments: regional Ministry of education and science, university, collage.

Activist is a student with limited functions of moderator. Activist will have an opportunity to make suggestions for consideration and election among the community and also moderate messages of a certain event. Activists can be heads/members of student self-government or other student associations in the region. The number of activists is limited for each region.

The students from the list of common users of the portal are appointed to this role by the moderators in the 
region. Moderator from the university or collage by receiving the status "Activist" views the list of users-students from his/her educational institution.

User is an individual person who has limited access to the system and carries out the following functions: viewing the materials; editing of the account and also filter setup of the events; publishing of messages and comments etc.

User can be anyone who wants (student, young person, member of subjects of the youth policy etc.) who have registered on the portal.

The important characteristic of the portal is maximum simple construction of the internal communication system because its setup is realized by the forces of the moderators that cannot disturb the work at the stages of implementation and testing.

Thus, with its own data bases and constructed hierarchy of a access level to the information portal "Muraveynik" will become a place for operative exchange of both internal information of the university, the region, the student association and external information among the members of the youth policy. The advantages of the suggested communication network are minimization of costs by information processing, protection from data loss, automation, control and controllability of interaction among remote users.

Implementation of the portal is planned on the second half of 2015 firstly in the test mode and then in fully functional mode.

\section{Conclusions}

Modern Russian youth and its more social active part- the students are now the main members of intercultural interaction under educational, social, scientific, leisure and another communication. Its high level of commitment to civil activity is noted. In this situation information isolation of communicators is seemed to be a dangerous barrier which hampers the formation of not only important social competences and complex development of a certain person but becomes a factor of development braking of the society as a whole. Especially it concerns the development of the regional societies developing away from the center. The answer for this challenge of modern times is the solution of an actual task of homogenization information space moreover in the educational sphere, overcoming of the discrecity of the educational space, the formation of effective channels of communication among the members of the youth policy. It is urgent especially for the regional universities because the development of the regional educational system is a key to the solution of many social and economical problems of the region, to its wellbeing and survival. One of the solutions of this task to date is the creation of effective strategy of systematization and ranking of the information by the regional universities. Mari State University implements this strategy through creation of the united information communication portal "Muraveynik" which is not only a specific interpretation of the development tasks faced by the regional universities but also a new reconsideration of cultural and sociological processes in the youth sphere.

\section{References}

Abrutyn, S. (2012). Toward A Theory of Institutional Ecology: The Dynamics of Macro Structural Space. Review of European Studies, 4(5), 167-180. http://dx.doi.org/10.5539/res.v4n5p167

Anagnou, E., \& Fragoulis, I. (2014). The Contribution of Mentoring and Action Research to Teachers' Professional Development in the Context of Informal Learning. Review of European Studies, 6(10). http://dx.doi.org/10.5539/res.v6n1p133

Elder, A. (2014). Excellent online friendships: An Aristotelian defense of social media. Ethics and Information Technology, 16, 287-297. http://dx.doi.org/10.1007/s10676-014-9354-5

Ershova, T., \& Shaposhnik, S. (2013). Use of Information and Communication Technologies by the Population of Russia and the European Union. Vestnik Rossiiskoi Akademii Nauk, 83(1), 23-30. http://dx.doi.org/10.1134/S1019331613010061

Farrugia, M., Hurley, N., Payne, D., \& Quigley, A. (2011). Social Network Construction in the Information Age. Views and Perspectives, 9, 131-132.

Gao, F., \& Bhiri, S. (2013). User Centric Complex Event Processing Based On Service Oriented Architectures. 28th Symposium on Applied Computing (p. 2). Coimbra. Portugal. http://dx.doi.org/10.1145/2480362.2480719

Khovanova, E. (2010). Intercultural communication in the educational space of the regional university (p. 20). Saratov. 
Kozlov, P., \& Obidina, Y. (2014). Volunteering as a factor in the formation of civic engagement of young people of the Republic of Mari El. Spiritual sphere of society, 11, 103-109.

Krasova, E., \& Neugodnikova, O. (2014). Social networks as a way of communication among students. RELGA, 12.

Kwok, L. (2015). A vision for the development of i-campus. Smart Learning Environments, 12. http://dx.doi.org/10.1186/s40561-015-0009-8

Marjolein, C., \& Herman, V. B. (2011). The role of Higher Education Institutions in building regional innovation systems. Papers in Regional Science, Wiley Blackwell, 271-286. http://dx.doi.org/10.1111/j.1435-5957.2010.00344.x

Obidina, Y. (2008). The future of higher education in Russia: Conference on "Shaping a common space of Education and Science of the Russian higher education: History and prospects. East-West, 1. 178-179.

Obidina, Y. (2010). The problem of Russian higher education: Law crisis and attempts to overcome it, Formation of a common space of education and science in Russia: Past, Present and Future. In Collection of hundred children-scientific conference devoted to the 55th anniversary of Professor AV Arsentieva (II Arsent'ev-cal reading) (pp. 258-262). Cheboksary: Chuvash State University.

Panagiotis, G., Adamantios, P., Efthymios, V., \& Adamos, A. (2011). Informatics and Communication Technologies (ICT) and In-service Teachers' Training. Review of European Studies, 3(1), 2. http://dx.doi.org/10.5539/res.v3n1p2

Rienties, B., \& Heliot, Y. (2013). Jindal-Snape D. Understanding social learning relations of international students in a large classroom using social network analysis. Higher Education, 66. 489-504.

Rogacheva, E. (2014). The implementation of new models of higher education institutions in modern conditions on an example of a regional university. Power, 6, 104-107.

Shalamova, L. (2011). Youth as a subject of social control activation of the potential of youth. Social-Humanities, 5, 79-86.

Sharypin, A. (2010). Volunteer movement: The origins and the present. Modern studies of social problems, 4, 214-220.

Tavokin, E. (2011). Mass Communication in the Modern World. Bulletin of the Russian Academy of Sciences, 81(11), 986-993. http://dx.doi.org/10.1134/S1019331611060062

Villanueva-Felez, A., Gallart J., \& Escriba-Esteve A. (2013). Measuring Personal Networks and Their Relationship with Scientific Production. Science and Technology Studies: Exploring the Knowledge Base, 51(4), 465-483. http://dx.doi.org/10.1007/s11024-013-9239-5

Yakoba, I. (2011). The impact of virtual social networks on youth. Bulletin of Irkutsk State TechnicalUniversity, 50(3), 287-292.

\section{Copyrights}

Copyright for this article is retained by the author(s), with first publication rights granted to the journal.

This is an open-access article distributed under the terms and conditions of the Creative Commons Attribution license (http://creativecommons.org/licenses/by/3.0/). 